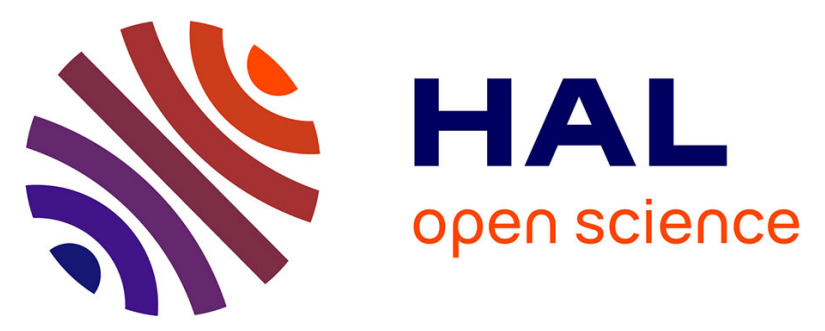

\title{
Relationship of the Central Indian Ridge segmentation with the evolution of the Rodrigues triple junction for the past 8 Myr.
}

\author{
Véronique Mendel, Daniel Sauter, Philippe Patriat, Marc Munschy
}

\section{To cite this version:}

Véronique Mendel, Daniel Sauter, Philippe Patriat, Marc Munschy. Relationship of the Central Indian Ridge segmentation with the evolution of the Rodrigues triple junction for the past 8 Myr.. Journal of Geophysical Research : Solid Earth, 2000, B7 (B7), pp.16563-16575. 10.1029/2000JB900098 . hal00104237

\section{HAL Id: hal-00104237 \\ https://hal.science/hal-00104237}

Submitted on 26 May 2020

HAL is a multi-disciplinary open access archive for the deposit and dissemination of scientific research documents, whether they are published or not. The documents may come from teaching and research institutions in France or abroad, or from public or private research centers.
L'archive ouverte pluridisciplinaire HAL, est destinée au dépôt et à la diffusion de documents scientifiques de niveau recherche, publiés ou non, émanant des établissements d'enseignement et de recherche français ou étrangers, des laboratoires publics ou privés. 


\title{
Relationship of the Central Indian Ridge segmentation with the evolution of the Rodrigues Triple Junction
}

\section{for the past 8 Myr}

\author{
Véronique Mendel $^{1}$ and Daniel Sauter \\ Ecole et Observatoire des Sciences de la Terre, Strasbourg, France
}

Philippe Patriat

Institut de Physique du Globe, Paris

Marc Munschy

Ecole et Observatoire des Sciences de la Terre, Strasbourg, France

\begin{abstract}
Located near $25^{\circ} 33^{\prime} \mathrm{S}, 70^{\circ} 00^{\prime} \mathrm{E}$, the Rodrigues Triple Junction is the joining point of the intermediate-spreading Southeast Indian and Central Indian Ridges with the ultraslow spreading Southwest Indian Ridge. Bathymetric data and magnetic anomalies are used to analyze the relationship between the evolution of the Central Indian Ridge segmentation and the evolution of the Rodrigues Triple Junction for the past $8 \mathrm{Myr}$. The Central Indian Ridge domain exhibits a complex morphotectonic pattern dominated by ridge-normal and oblique bathymetric lows interpreted as the off-axis traces of axial discontinuities. The short-lived nontransform discontinuities as well as the segments that lengthen or shorten along the ridge axis reveal that the Central Indian Ridge segmentation is unstable near the Rodrigues Triple Junction. The combined study of the Central Indian Ridge and Southeast Indian Ridge domains shows that the triple junction evolves between two modes: a continuous mode where the Central Indian Ridge and Southeast Indian Ridge axes are joined and a discontinuous mode where the two ridge axes are offset. Owing to spreading asymmetry, and differences in axis direction or in lengthening rates of the Central Indian and Southeast Indian ridges, the continuous mode is unstable and evolves rapidly ( $<2 \mathrm{Myr}$ ) into a discontinuous mode. This last one is more stable and can evolve into a continuous mode only through the formation of a new Central Indian Ridge segment, which takes place facing the northern Southeast Indian Ridge segment. The evolution of the Rodrigues Triple Junction configuration and the evolution of the Central Indian Ridge segmentation are thus closely related.
\end{abstract}

\section{Introduction}

The Rodrigues Triple Junction (RTJ), also called Indian Ocean Triple Junction $\left(25^{\circ} 33^{\prime} \mathrm{S}, 7^{\circ} 00^{\prime} \mathrm{E}\right)$ joins the intermediate spreading Central Indian Ridge (CIR; $50 \mathrm{~km} / \mathrm{Myr}$ ) and Southeast Indian Ridge (SEIR; $60 \mathrm{~km} / \mathrm{Myr}$ ) and the ultraslow spreading Southwest Indian Ridge (SWIR; 16 km/Myr) (Figure 1). The RTJ was first recognized by McKenzie and Sclater [1971]. It is a stable ridge-ridge-ridge (RRR) type triple junction at a regional scale and has existed since at least $65 \mathrm{Ma}$ [Patriat and Ségoufin, 1988]. For the last $10 \mathrm{Myr}$, the triple junction evolution is well described by a RRR-type velocity diagram with the CIR and SWIR lengthening obliquely and the SEIR keeping a constant length [Tapscott et al., 1980].

The topographic characteristics of the three median valleys were described by Munschy and Schlich [1989] using a Sea Beam

\footnotetext{
${ }^{1}$ Now at Southampton Oceanography Centre, Challenger Division for Seafloor Processes, Southampton, England, United Kingdom.

Copyright 2000 by the American Geophysical Union.

Paper number 2000JB900098.

0148-0227/00/2000JB900098\$09.00
}

bathymetric survey of a $100 \mathrm{~km} \mathrm{x} 100 \mathrm{~km}$ area around the triple junction. From GLORIA side-scan sonar images, Mitchell [1991a] suggested that the hypothesis of rigid plate tectonics may not apply in a fine scale at the RTJ because extension of the crust across the SWIR is distributed over a $10 \mathrm{~km}$ or more wide zone. Sea Beam and GLORIA data of the trace of the RTJ on the Antarctic plate (0-20 Ma) also showed sections with series of en échelon escarpments that contrast with long linear scarps, suggesting two modes, discontinuous and continuous, of the triple junction evolution [Patriat and Parson, 1989; Mitchell and Parson, 1993]. Recently, the analysis of Simrad multibeam data over the SWIR domain for the last $8 \mathrm{Myr}$ revealed two ways of lengthening of the SWIR: (1) a continuous and progressive propagation of the SWIR with distributed deformation in preexisting crust of the CIR and (2) a discontinuous propagation of the SWIR with focusing of the deformation in a rift zone when the triple junction migrates rapidly to the north [Sauter et al., 1997].

Mitchell and Parson [1993] and Honsho et al. [1996] related changes in the spreading processes of the CIR to the evolution of the RTJ. Periods of asymmetric spreading on the CIR may possibly indicate that the CIR and SEIR have been offset by a fracture zone at the triple junction during one of the two modes 
Table 1. Compilation of All Bathymetric Data Used for This Study

\begin{tabular}{lccccc}
\hline \multicolumn{1}{c}{ Cruise } & Research Vessel & Year & Location & Echo Sounder & References \\
\hline Rodriguez I and II & Jean Charcot & 1984 & RTJ & Sea Beam & Schlich et al. $[1987]$ \\
Gemino III & Sonne & $1987-1988$ & CIR & Sea Beam & Plüger et al. $[1990]$ \\
MD61 & Marion Dufresne & 1989 & CIR & Monobeam & Schlich et al. $[1989]$ \\
Hydrotrunc & Sonne & 1993 & CIR & Hydrosweep & Halbach et al. $[1995]$ \\
Capsing & L'Atalante & 1993 & SWIR & Simrad & Patriat et al. [1997] \\
KH93-3 & Hakuho Maru & 1993 & SEIR & Sea Beam & Honsho et al. [1996] \\
Hydrock & Meteor & 1995 & CIR & Hydrosweep & Lochte et al. $[1995]$ \\
\hline
\end{tabular}

The Sea Beam bathymetric survey system uses a multnarrow echo sounder $(12 \mathrm{kHz})$ which allows a maximum swath width corresponding to three fourths of the water depth [Renard and Allenou, 1979]. Expanding on the Sea Beam design, the Hydrosweep system (15.5 kHz) provides a wider swath width (twice the water depth) [De Moustier, 1988]. The Simrad EM12D forms part of the new generation of deep sea sonar surveying tools [Bourillet et al, , 1996]. It is a $13 \mathrm{kHz}$ multi-narrow-beam echo sounding system which can cover a sector of $150^{\circ}$, which represents a swath width of up to 7 times the water depth.

[Mitchell and Parson, 1993]. However, the lack of data over the triple junction trace on the Capricorn plate could not confirm the ridge-ridge-transform fault (RRF) evolution of the RTJ. Honsho et al. [1996] presented a new conceptual evolution model for the discontinuous mode that includes a short-living $(<0.5 \mathrm{Myr})$ northward propagation of the SEIR (of $\sim 25-30 \mathrm{~km}$ ) followed by lengthening of the SWIR, failing of the SEIR propagation rift and restoration of the CIR in less than $\sim 0.1$ Myr. However, the pseudo faults associated with those propagating rifts were not observed on the bathymetric chart of the triple junction area [Honsho et al., 1996]. How the segmentation of the CIR changes while this ridge is lengthening southward and whereas the triple junction evolves with two modes was thus still unclear because bathymetric and magnetic data were lacking on the flanks of the CIR.

In this study we describe the evolution of the CIR domain, and to a lesser extent the SEIR domain, since anomaly 4 (8 Ma) using a compilation of bathymetric and magnetic data collected during several cruises in the RTJ area. We first analyze the variations of the spreading rates on the flanks of the CIR and SEIR. We then propose a location for the southeastern limit of the CIR domain (the Capricorn trace of the triple junction) and confirm that an offset has existed between the CIR and SEIR during one of the modes of evolution of the triple junction. We then determine the evolution in time and space of the segments and discontinuities of the CIR domain. Finally, we show that the evolution of the segmentation along the CIR and the evolution of the triple junction are strongly related.

\section{Main Topographic Characteristics of the Indian Ridges at the RTJ}

We only give here a summary of the characteristics of the three axial valleys in the RTJ area, as they were extensively described by Munschy and Schlich [1989], Mitchell [1991a, b], Briais [1995], Honsho et al. [1996], and Sauter et al. [1997]. We then focus on the segmentation evolution of the CIR and SEIR from magnetic and bathymetric data. We used multibeam data collected during eight cruises (1984-1995; Table 1 and Figure 1) with various bathymetric systems (monobeam, Sea Beam, Hydrosweep, and Simrad) to produce the most complete bathymetric grid of the RTJ area (Figures $2 a$ and $2 b$ ).

The topography of the RTJ area (Figures $2 a$ and $2 b$ ) is dominated by the deep SWIR domain bounded by two asymmetric bathymetric highs with steep scarps facing toward the SWIR and gentle slopes facing away. These bathymetric features correspond, at a regional scale, to the RTJ traces which separate the seafloor generated at the SWIR from the seafloor generated at the SEIR and the CIR on the Antarctic and African plates respectively. These RTJ traces draw a large $V$ pointing toward the northeast and showing the lengthening of the SWIR [Mitchell, 1991a]. The African RTJ trace is relatively continuous from $68^{\circ} 00^{\prime} \mathrm{E}$ to $69^{\circ} 50^{\prime} \mathrm{E}$ except a small dextral offset at $68^{\circ} 27^{\prime} \mathrm{E}$. The strike of the African RTJ trace varies between $N 65^{\circ} \mathrm{E}$ and $\mathrm{N} 95^{\circ} \mathrm{E}$; it is different from the mean spreading direction of the CIR $\left(\mathrm{N} 60^{\circ} \mathrm{E}\right.$ ), indicating that the CIR lengthened toward the southeast at different rates. By contrast, the Antarctic RTJ trace is only continuous and linear from $69^{\circ} 29^{\prime} \mathrm{E}$ to $69^{\circ} 49^{\prime} \mathrm{E}$ near its eastern

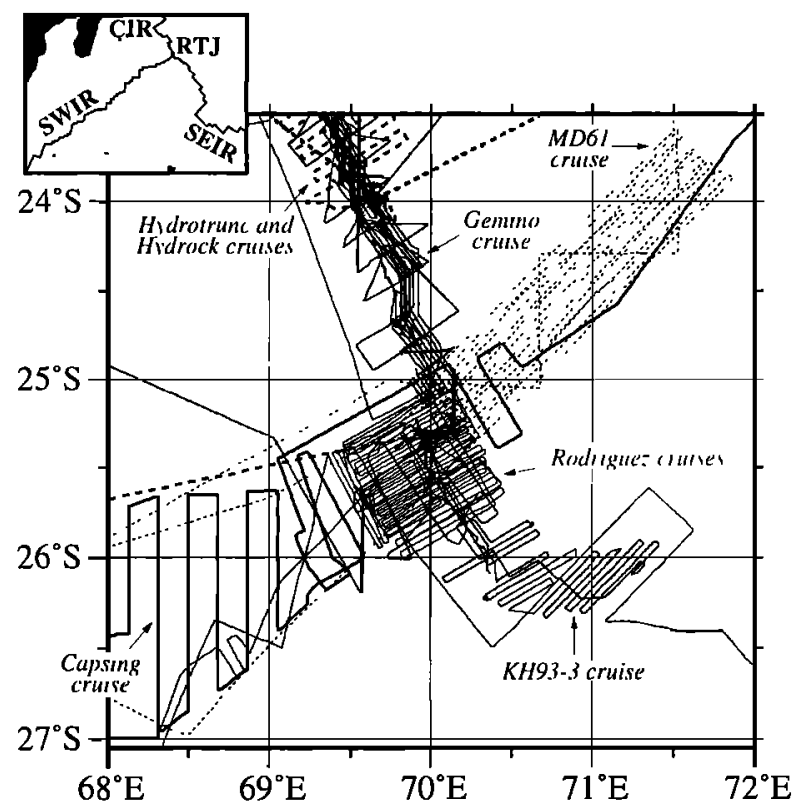

Figure 1. Track chart of the study area. Ship tracks from Simrad, Hydrosweep, and Sea Beam multibeam bathymetry cruises are indicated by solid bold, dashed bold, and solid thin lines, respectively (see Table 1). Ship track from the MD61 cruise is indicated by a thin dotted line. CIR, Central Indian Ridge; RTJ, Rodrigues Triple Junction; SWIR, Southwest Indian Ridge; SEIR, Southeast Indian Ridge. 


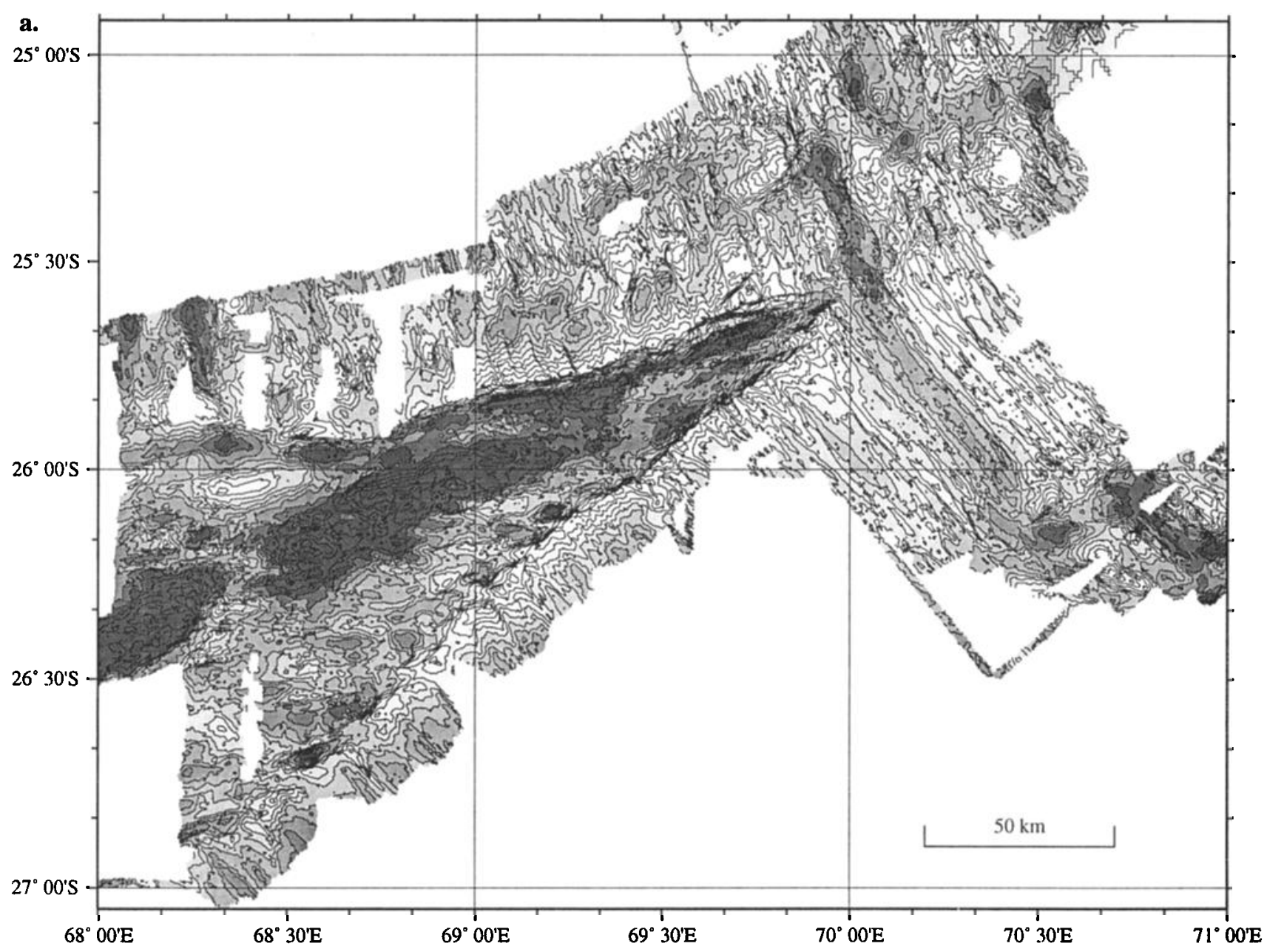

Figure 2. Bathymetry of the Rodrigues Triple Junction area. Contour interval is $200 \mathrm{~m}$. Grids were computed with a spatial resolution of $120 \mathrm{~m}$ using the multibeam bathymetric data and merged with an other grid that was computed with a pixel spacing of only $1 \mathrm{~km}$ using the monobeam bathymetric data of the MD61 cruise.

end. Elsewhere, it corresponds to a series of en échelon fault scarps with $3-5 \mathrm{~km}$ offsets to the north every $10-28 \mathrm{~km}$ [Sauter et al., 1997]. The strike of the Antarctic RTJ trace varies between $\mathrm{N} 41^{\circ} \mathrm{E}$ and $\mathrm{N} 59^{\circ} \mathrm{E}$ with a mean value, $\mathrm{N} 48^{\circ} \mathrm{E}$, parallel to the mean spreading direction of the SEIR. These small variations indicate that periods of slight lengthening and shortening of the SEIR have altemated and that this ridge kept an almost constant length since $8 \mathrm{Ma}$.

The SWIR domain bounded by these two RTJ traces is deeper (mean depth $\sim 4200 \mathrm{~m}$ ) and more rugged than the seafloor generated at the CIR or the SEIR (mean depth $\sim 3100 \mathrm{~m}$ ). Between $68^{\circ} 10^{\prime} \mathrm{E}$ and $69^{\circ} 25^{\prime} \mathrm{E}$, the southern flank of the SWIR domain is wider than the northern flank and is characterized by a series of en échelon bathymetric highs similar in shape, size, and orientation to the high centered at $69^{\circ} 30^{\prime} \mathrm{E}$ near the present-day triple junction [Sauter et al., 1997]. The easternmost segment of the SWIR in the study area is centered at $68^{\circ} 22^{\prime} \mathrm{E}$, about $200 \mathrm{~km}$ from the RTJ, over a bathymetric high topped by a volcanic ridge [Rommevaux-Jestin et al., 1997; Mendel et al., 1997].

Within the survey area the CIR axial domain consists of two segments (segments 1 and 2 in the nomenclature of Briais [1995] starting from the RTJ). They are trending $N 150^{\circ} \mathrm{E}$ and are 40 and $50 \mathrm{~km}$ long, respectively [Briais, 1995]. A nontransform discontinuity (NTD) offsets them, at $25^{\circ} 10^{\prime} \mathrm{S}$, by $\sim 20 \mathrm{~km}$. The northwestern segment of the SEIR, which joins the RTJ, is $85 \mathrm{~km}$ long and trends $\mathrm{N} 140^{\circ} \mathrm{E}$ [Honsho et al., 1996]. To the south, at about $26^{\circ} 05^{\prime} \mathrm{S}$, it is bounded by a left-lateral transform fault which offsets the SEIR axis by $\sim 26 \mathrm{~km}$ [Honsho et al., 1996].

\section{Variation of the Spreading Rates on the Flanks of the CIR and SEIR}

Magnetic anomalies have been identified by comparison between all available magnetic profiles in the area, collected during 18 cruises (1960-1995), and synthetic magnetic anomaly profiles which were computed for the CIR and the SEIR (Figure 3). We picked each magnetized block boundary at anomalies 1 (0-0.78 Ma), Jaramillo (0.99-1.07 Ma), 2 (1.77-1.95 Ma), 2a (2.581-3.58 Ma), 3 (4.18-5.23 Ma), 3a (5.894-6.567 Ma), and 4 (7.432-8.257 Ma) (geomagnetic reversal timescale of Cande and Kent [1995]; Figure 4). These crossings are shown on the structural map of the RTJ area (Figure 5). Owing to their very low amplitudes, magnetic anomalies over the SWIR east of $68^{\circ} 30^{\prime} \mathrm{E}$ are difficult to interpret: the Brunhes anomaly is not recognizable until farther west at $68^{\circ} 15^{\prime} \mathrm{E}$ [Tapscot: $t$ al., 1980]. There are two explanations for this [Patriat and Parson, 1989]: first, the SWIR spreading rate is very slow $(<8 \mathrm{~km} / \mathrm{Myr})$ and the magnetic reversal is more difficult to interpret; second, the SWIR 


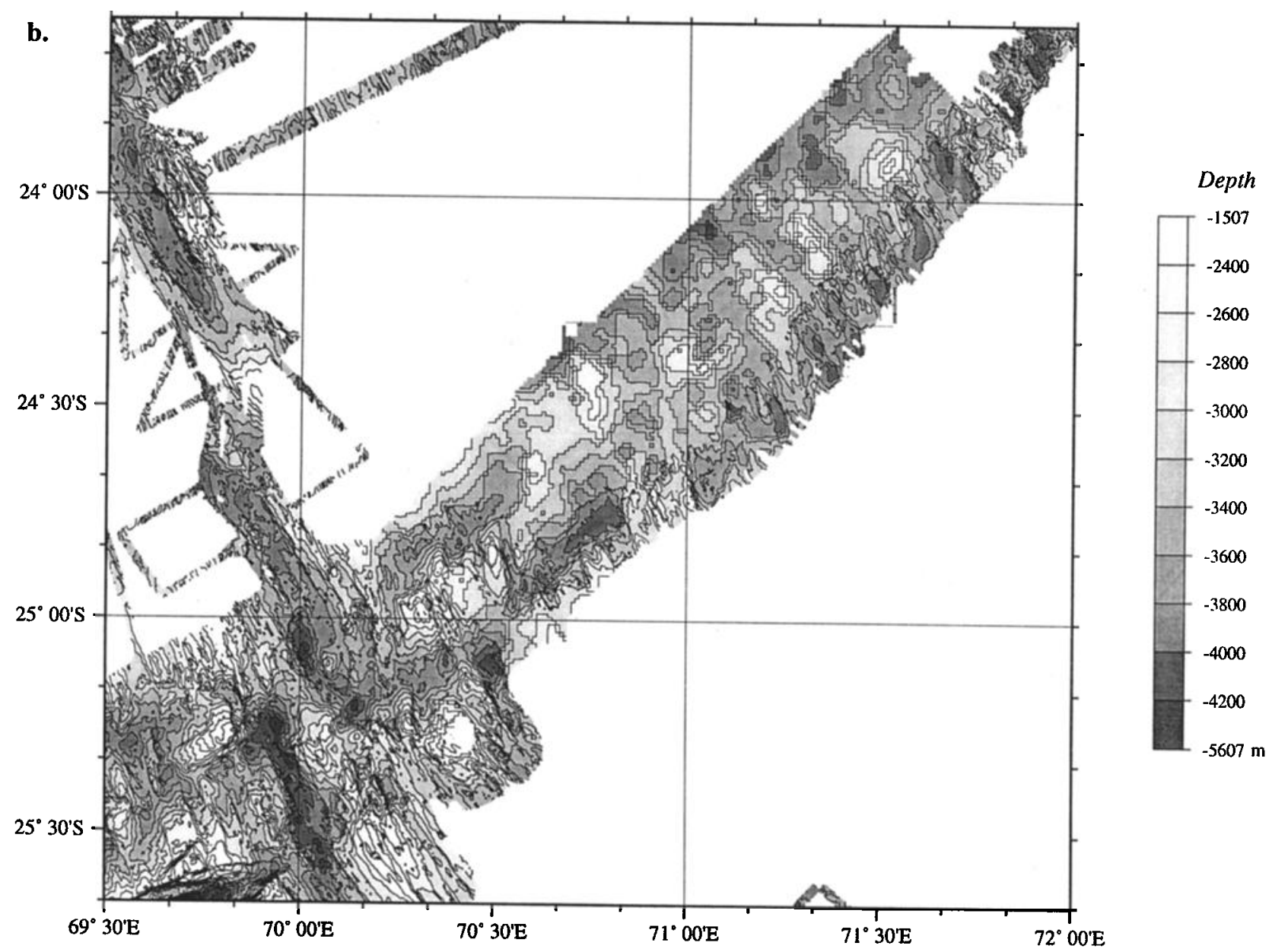

Figure 2. (continued)
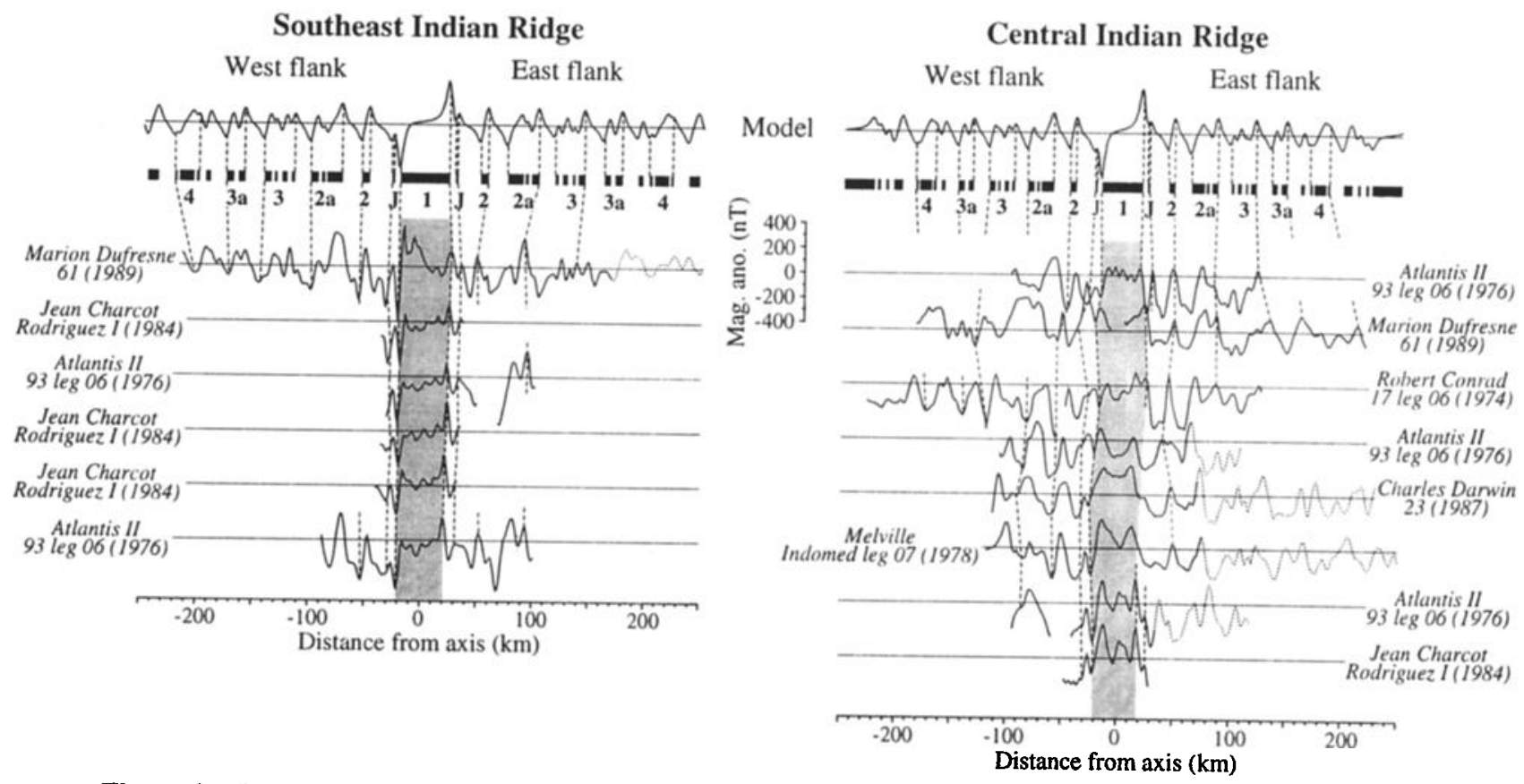

Figure 3. (bottom) Interpretation of some magnetic profiles across the Southeast Indian Ridge and the Central Indian Ridge. (top) The synthetic profiles derive from the geomagnetic reversal timescale of Cande and Kent [1995] and a two-dimensional model consisting of a flat layer of $300 \mathrm{~m}$ thickness at a depth of $3000 \mathrm{~m}$ with a spreading rate of $47 \mathrm{~km} / \mathrm{Myr}$ for the Central Indian Ridge and of $52 \mathrm{~km} / \mathrm{Myr}$ for the Southeast Indian Ridge. Each profile is identified by the name of the research vessel, the name of the cruise, and the year when the profile was acquired. 


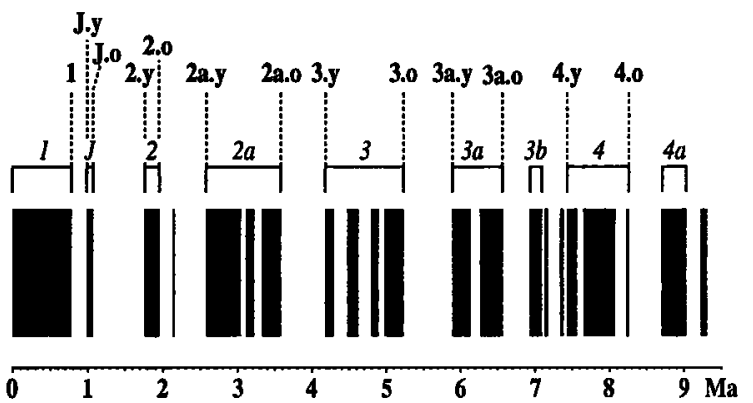

Figure 4. Magnetic anomalies and selected isochrons (1-4.o) after the geomagnetic reversal timescale of Cande and Kent [1995].

axis has a general trend which is not orthogonal to the spreading direction and may be cut by closely spaced short offsets or characterized by oblique spreading sections. Hereafter we will refer to the different anomalies by preceding their names by a $\mathrm{A}$ for Anomaly.

The half spreading rates of the SEIR and the CIR have been determined between successive isochrons along great circles oriented $\mathrm{N} 48^{\circ} \mathrm{E}$ and $\mathrm{N} 60^{\circ} \mathrm{E}$, respectively. In order to smooth errors due to uncertainties in both the location of magnetic boundaries and the magnetic reversal scale, we only considered distances between isochrons separated by at least $0.6 \mathrm{Myr}$
( $>10 \mathrm{~km}$ ). Wherever possible, we measured distances between isochrons in several locations. The half spreading rates given in Table 2 are averages of these different measurements. Uncertainties on mean half spreading rates average $2.0 \mathrm{~km} / \mathrm{Myr}$ for the SEIR and $2.3 \mathrm{~km} / \mathrm{Myr}$ for the CIR. The variation of full spreading rate and asymmetry are presented in Figures $6 \mathrm{a}, 6 \mathrm{~b}$, and $6 c$.

Concerning the SEIR, the mean full spreading rate is $52 \mathrm{~km} / \mathrm{Myr}$ for the last $8 \mathrm{Myr}$. Some periods of slower spreading, like the A2a.o-A3.y and A3a.o-A4.y periods, and periods of faster spreading, like the A3.y-A3.o and A3a.y-A3a.o periods, are observed (Figure 6a). Spreading of the SEIR is symmetric since A3.y and asymmetric between A3.y and A4.o, with a half spreading rate $13 \%$ greater for the east flank than for the west one (Figure 6c). Note that this asymmetry was determined with few anomalies, especially from A3a.o to A4.o for the east flank. However, these results are in agreement with those of Royer and Schlich [1988], who observe an asymmetry of spreading before A3.y on the SEIR between $25^{\circ} 30^{\prime} \mathrm{S}$ and $27^{\circ} \mathrm{S}$. Concerning the CIR, the mean full spreading rate is $47 \mathrm{~km} / \mathrm{Myr}$ for the last $8 \mathrm{Myr}$. Like the SEIR, periods of slower spreading (A2a.y-A2a.o and A3a.o-A4.y) alternate with periods of faster spreading (A2.yA2a.y and A4.y-A4.o) (Figure 6a). The CIR was spreading asymmetrically since $\mathrm{A} 1$, generating, on average, $33 \%$ more crust on the west flank than on the east one, and between A2a.o and A4.y, generating $21 \%$ more crust on the east flank than on the west one (Figure 6b).

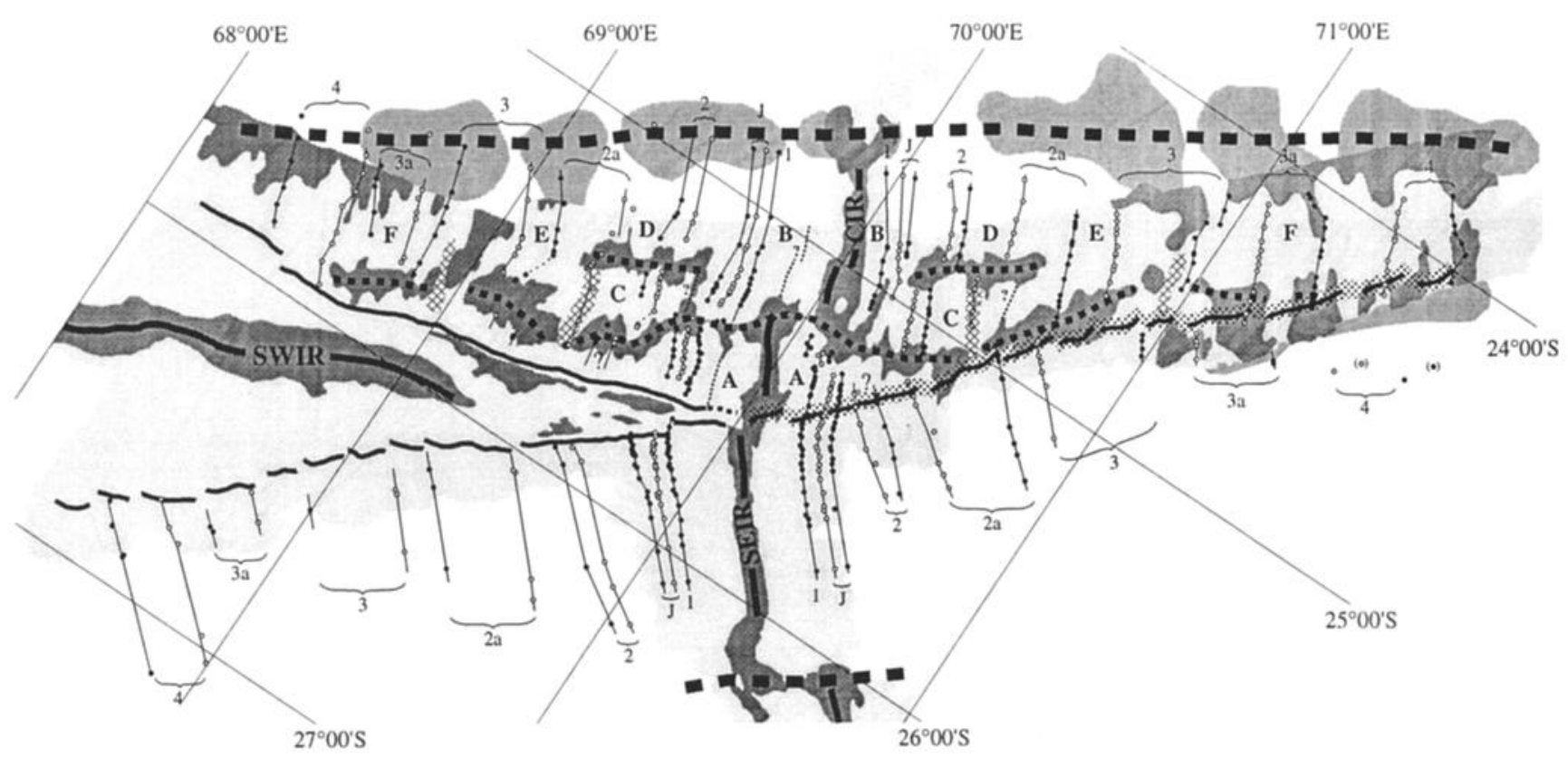

Figure 5. Structural map of the Rodrigues Triple Junction area. The dark shaded areas correspond to bathymetric lows, while the light shaded areas correspond to bathymetric highs and limit the bathymetric survey area. The medium shaded areas correspond to altimetric lows. Nontransform discontinuities associated to these lows are shown as bold dashed lines. Letters identify the Central Indian Ridge spreading segments discussed in text. The axes of Indian ridges are shown as bold lines. The anomalies identified are shown by open circles and solid circles which correspond to youngest and oldest boundaries of magnetized blocks, respectively. Thin solid lines represent the isochrons. Solid lines correspond to the African and Antarctic triple junction traces and to the location of the Capricorn triple junction trace deduced from the rotation of the Antarctic triple junction trace onto the Capricorn plate. The stippled area reflects the uncertainties of the location of the Capricorn triple junction trace. The large troughs observed on the Central Indian Ridge domain and interpreted as traces of Central Indian Ridge axis jumps are shown by thin dotted lines. Abyssal hills disrupting nontransform discontinuities (cross-hatched) are observed on either side of the Central Indian Ridge axis. 
Table 2. Anomaly Interval Half Spreading Rates on the SEIR and the CIR

\begin{tabular}{|c|c|c|c|c|c|}
\hline \multirow[t]{2}{*}{ Anomalies } & \multirow[t]{2}{*}{$\Delta \mathrm{t}, \mathrm{Myr}$} & \multicolumn{2}{|c|}{$\begin{array}{c}\text { SEIR } \\
\text { Half Spreading Rate, km/Myr }\end{array}$} & \multicolumn{2}{|c|}{$\begin{array}{c}\text { ClR } \\
\text { Half Spreading Rate, } \mathrm{km} / \mathrm{Myr}\end{array}$} \\
\hline & & West Flank & East Flank & West Flank & East Flank \\
\hline \multirow[t]{2}{*}{ Axis - 1} & 0.780 & 28.3 & 25.5 & Seg. A: 30.3 & 19.5 \\
\hline & & & & Seg. B: 35.9 & 13.9 \\
\hline \multirow[t]{2}{*}{$1-2 . y$} & 0.990 & 27.7 & 25.7 & Seg. C: 33.2 & 13.1 \\
\hline & & & & Seg. D: 24.2 & 22.1 \\
\hline \multirow[t]{2}{*}{$2 . y-2 a . y$} & 0.811 & 29.7 & 26.5 & Seg. C: 29.4 & 25.5 \\
\hline & & & & Seg. D: 29.4 & 25.5 \\
\hline \multirow[t]{2}{*}{ 2a.y-2a.o } & 0.999 & 27.1 & 26.2 & Seg. C: 13.4 & 27.1 \\
\hline & & & & Seg. D: 20.9 & 19.6 \\
\hline $2 a .0-3 . y$ & 0.600 & 20.9 & 23.0 & 18.6 & 24.1 \\
\hline $3 . y-3.0$ & 1.050 & 28.1 & 32.4 & 25.4 & 24.2 \\
\hline $3.0-3 a . y$ & 0.664 & 24.8 & 27.0 & 13.8 & 33.0 \\
\hline 3a.y - 3a.o & 0.673 & 23.0 & 36.8 & 20.7 & 29.8 \\
\hline $3 a .0-4 . y$ & 0.865 & 13.2 & 21.8 & 8.9 & 26.5 \\
\hline $4 . y-4.0$ & 0.825 & 22.6 & 28.4 & 26.5 & 25.0 \\
\hline
\end{tabular}

Half spreadıng rates of the Southeast Indian and Central Indian Ridges have been determıned between successive isochrons in a $\mathrm{N}^{\circ} 8^{\circ} \mathrm{E}$ and $\mathrm{N} 60^{\circ} \mathrm{E}$ direction respectively, where the time span between these isochrons was $>0.6 \mathrm{Myr}$. For the Central Indian Ridge, wherever possible, half spreading rates were determıned over each segment (A, B, C, etc.) shown in Figure 5. Before anomaly 2a old, half spreading rates on the Central Indian Ridge were measured over segments $E$ and $F$ (Figure 5). The mean error of half spreading rates is $\sim 2.0 \mathrm{~km} / \mathrm{Myr}$ for the Southeast Indian Ridge and $2.3 \mathrm{~km} / \mathrm{Myr}$ for the Central Indian Ridge.

\section{Southeastern Limit of the CIR Domain: Capricorn Trace of the Triple Junction}

Owing to their close spreading rates, the CIR and the SEIR have generated seafloor with similar characteristics of depth and roughness. For the last $1 \mathrm{Myr}$, small changes of SEIR abyssal hills direction toward the CIR domain can be used to locate the boundary area between the CIR and SEIR domains on the Capricom plate (Figures $2 a$ and $2 b$ ). These small strike changes are associated with the deepening of the SEIR and CIR abyssal hills toward the CIR and SEIR domains (Figures $2 a$ and $2 b$ ), respectively. Unfortunately, the strike of the abyssal hills older than 1 Myr cannot be precisely determined because multibeam bathymetric data are lacking further to the northeast. The position of the Capricorn RTJ trace must therefore be determined arbitrarily in order to indicate the probable locations where the SEIR and CIR should meet between $8 \mathrm{Ma}$ and $\mathrm{l} \mathrm{Ma}$. For this purpose, we have rotated the Antarctic RTJ trace onto the Capricom plate. Plate reconstruction vectors, age, and location of the Antarctic RTJ trace are needed to perform this rotation. Because the SWIR domain near the RTJ results mostly from tectonic extension of SEIR and CIR preexisting crust [Sauter et al., 1997], it is difficult to locate accurately the boundary between the SWIR domain and the CIR and SEIR domains. Moreover, the foot of the series of the large normal fault scarps corresponding to the RTJ traces at a regional scale is buried by numerous talus produced by mass wasting processes. We therefore chose to pick the position of the triple junction traces on the summit of these large escarpments that can be followed with ease on the bathymetric map. The resulting error of location is $\sim 2-3 \mathrm{~km}$ (the mean half width of the deformation zone in the SWIR domain near the triple junction [Sauter et al., 1997]). A similar offset will thus exist between the predicted triple junction trace on the Capricom plate and the position of the trace itself. The age of the Antarctic RTJ trace has been determined by lengthening the isochrons of the SEIR until the trace in a $N 138^{\circ} \mathrm{E}$ direction.
Between the isochrons, the age of the trace is linearly interpolated. We then used rotations given by Royer and Schlich [1988], which allow to obtain a satisfying fit between the crossings of the SEIR on the Capricorn plate and the rotated ones of the Antarctic plate. We have not used the projection of the African RTJ trace to confirm the position of the RTJ trace on the Capricom plate because the lack of magnetic profiles near the African RTJ trace does not allow a well-constrained age determination for this trace. Moreover, it has been previously suggested by Mitchell and Parson [1993] and Sauter et al. [1997] that northward relocalizations of the SWIR rifting may have enclosed part of the series of normal faults, which characterized the African RTJ trace close to the RTJ [see Sauter et al., 1997, Figure 11], within the Antarctic plate, leaving little evidence for a precise location of the triple junction trace on the African plate. Between A3.o and the present day, GLORIA images show that the predicted Capricom RTJ trace falls within a wide transition area with, to the south, bathymetric features parallel to the SEIR abyssal hills, and to the north, lineations striking parallel to the CIR abyssal hills [Mitchell and Parson, 1993]. Before A2a.o the predicted Capricorn RTJ trace falls at the southern edge of a wide and continuous bathymetric low that we have interpreted as the off-axis trace of an axial discontinutty (Figure 5). Since we used the top of the escarpments of the Antarctic RTJ trace, the triple junction trace on the Capricom plate should be located $\sim 2-3 \mathrm{~km}$ more to the northwest along the deepest part of the bathymetric low. The bathymetric trace of this NTD to the west of the RTJ is present in the CIR domain for the same ages but partly buried by the uplift of the structures near the African RTJ trace (Figure 2a) due to isostatic compensations [Mitchell and Parson, 1993]. The section of the predicted Capricorn RTJ trace before A2a.o is associated with 14-23 km long offsets, measured along the trace, between the CIR and SEIR isochrons (Figure 5). These offsets are difficult to identify on the western CIR and SEIR flanks by rotating the Antarctic RTJ trace onto the African plate using the rotations of Chu and Gordon [1999] for the SWIR. We suggest 
that since the distributed deformation prevents an accurate location of the triple junction traces, especially for the African RTJ trace, it also precludes accurate reconstructions of the offsets on the African and Antarctic plates.

We thus conclude that as in the present-day configuration of the RTJ where there is a small $\sim 5 \mathrm{~km}$ offset between the CIR and SEIR axes [Munschy and Schlich, 1989], an axial discontinuity has existed at the triple junction before A2a.o. By contrast, between $\mathrm{A} 1$ and $\mathrm{AJ}$, the isochrons are continuous across the predicted Capricorn RTJ trace showing only a slight change of strike (Figure 5). Between AJ and A2a.y, the lack of well-identified magnetic anomalies does not allow us to be certain that there is no offset. However, the predicted RTJ trace crosses a bathymetric domain where the abyssal hills show a slight change of strike but neither interruption nor offset (Figures $2 \mathrm{a}$ and 7).

\section{Evolution of the CIR Segmentation}

The CIR domain is bounded to the north by the off-axis traces of the NTD (24\%30'S) between segments 2 and 3 that exists since $\sim 10 \mathrm{Ma}$ (bold dotted line in Figure 5). This domain exhibits a complex morphotectonic pattern dominated by ridge-normal and oblique bathymetric lows that disrupt isochrons and are interpreted consequently as the off-axis traces of axial discontinuities (bold dotted lines in Figure 5). These troughs partition the ridge flanks into rhomb-shaped areas of relatively higher elevation which can be associated to the off-axis traces of segment centers. These areas are formed by a series of abyssal hills, lineated more or less parallel to the present CIR axis (N150$160^{\circ} \mathrm{E}$ ), and spaced by $\sim 2-8 \mathrm{~km}$. Near the off-axis discontinuities, some abyssal hills curve toward the troughs showing the sense of the offsets.

We have identified six major rhomb-shaped areas on the west flank with their conjugates on the east flank (A-F in Figure 5). The oldest one, i.e., area F, is limited to the north by the $24^{\circ} 30^{\prime} \mathrm{S}$ NTD off-axis traces and to the south by the RTJ traces from 9 to $\sim 7 \mathrm{Ma}$ (between A4.y and A3a.o) and by a N60 ${ }^{\circ}$ E NTD from $\sim 7$ to $-4.7 \mathrm{Ma}$ (between A3.0 and A3.y). Segment $F$ was $\sim 25 \mathrm{~km}$ long at $\sim 9 \mathrm{Ma}$ (A4a.o). It has lengthened to the south by $\sim 25 \mathrm{~km}$ during $\sim 2$ Myr and has kept a constant length afterward $(\sim 50 \mathrm{~km})$. It is separated from area $\mathrm{E}$ by a north-south bathymetric trough (Figure 5) that we interpret as being produced during a major tectonic extensional period at about 4.7 Ma. From

Figure 6. (a) Evolution of the full spreading rate along the Central Indian and Southeast Indian Ridges for the last $8 \mathrm{Myr}$. Dashed lines are mean spreading rates. Shaded stripes are associated to the uncertainties. (b) and (c) Evolution of the spreading asymmetry along the Central Indian and Southeast Indian Ridges, for the last $8 \mathrm{Myr}$. This percentage has been calculated using mean half spreading rates (Table 2) and is positive when there is more crust created on the west flank than on the east flank and negative in opposite case. Shaded stripes correspond to the error of percentage relative to errors of distance measurements between isochrons. (d) Evolution of the apparent offset between the Southeast Indian Ridge and Central Indian Ridge isochrons. These offsets are measured along the predicted Capricorn triple junction trace. Between anomaly $2 \mathrm{a}$ young and anomaly 1 , the curvature of the Central Indian Ridge and Southeast Indian Ridge isochrons close to the Capricorn triple junction trace compensates for the real offsets leaving apparent zero offsets.
-4.7 to $\sim 3 \mathrm{Ma}$ (between A2a.o and A2a.y), segment E, which was initially $50 \mathrm{~km}$ long, has lengthened to the south by $\sim 15 \mathrm{~km}$. At -3 Ma a new NTD separated this segment $E$ in two new segments (D and C). From $\sim 3$ to $\sim 1.3 \mathrm{Ma}$ (between A2.y and AJ.o), segment $D$ has kept a constant length, $45 \mathrm{~km}$, while the length of

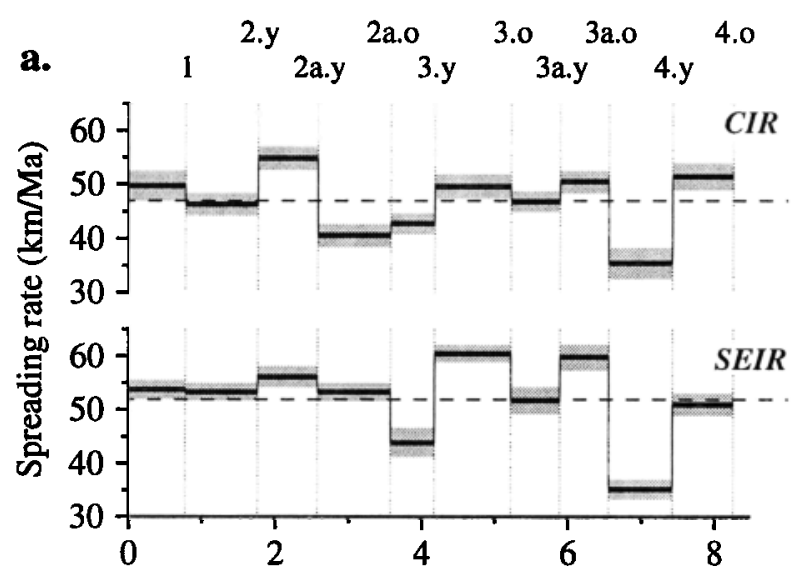

\section{b. CIR}
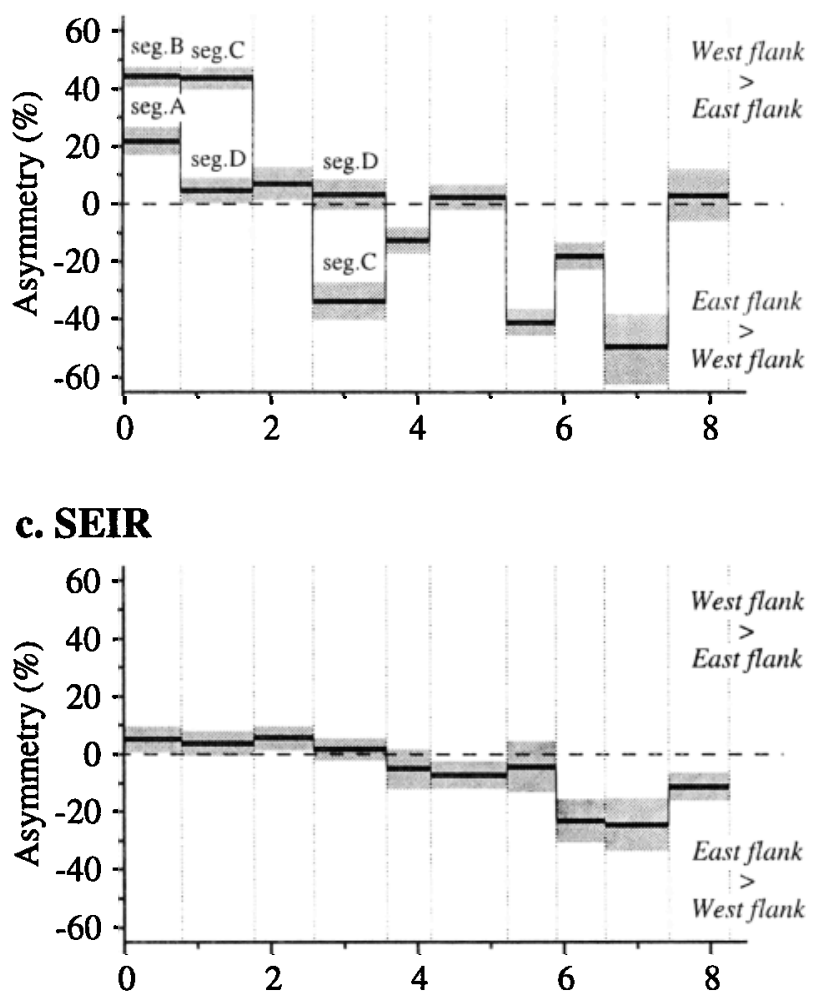

d.

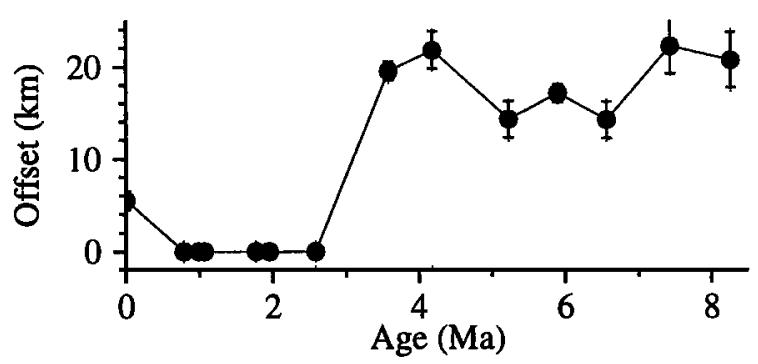




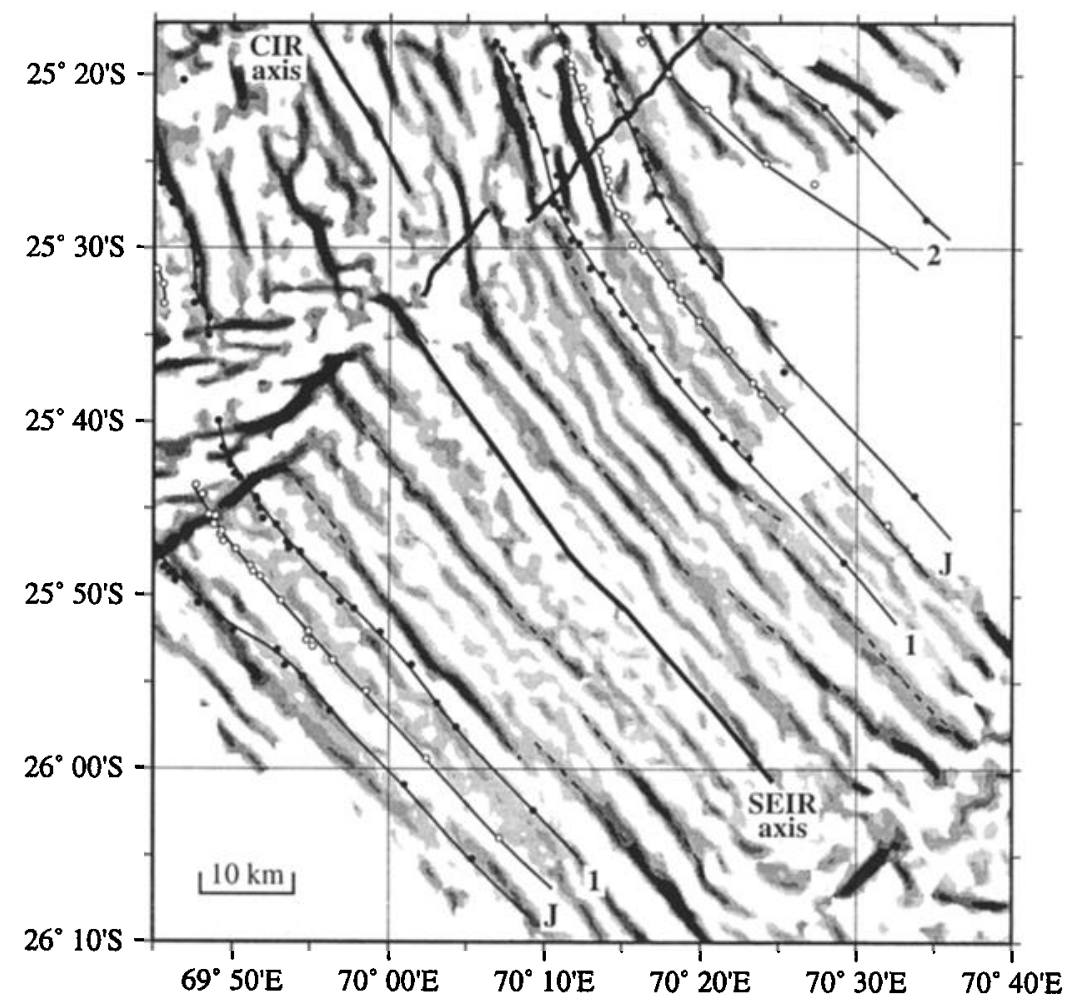

Figure 7. The abyssal hill system of the Southeast Indian Ridge enhanced by calculating the principal curvatures at each pixel of the bathymetric grid. Shaded areas correspond to ridges. The shading scale is related to the amplitude of the ridge: solid areas correspond to ridges that are well marked in the topography. Successive ridges and troughs are found at about the same age on each flank.

segment $C$ has varied between 16 and $27 \mathrm{~km}$. Discontinuity D-C was a small right-stepping offset (about $8 \mathrm{~km}$ ). It disappeared at $\sim 1.3 \mathrm{Ma}$, when segments $C$ and $D$ joined together to create a new $60 \mathrm{~km}$ long segment, segment $B$, which corresponds to the offaxis trace of the present-day CIR segment 2. During the last $1 \mathrm{Myr}$, this segment has shortened by $\sim 10 \mathrm{~km}$. On the west flank, segment $B$ is characterized by the presence of a topographic high (centered at $69^{\circ} 46^{\prime} \mathrm{E}-25^{\circ} 17^{\prime} \mathrm{S}$ ), which was interpreted by Mitchell et al. [1998] as a corrugated surface. At about $2.6 \mathrm{Ma}$ (A2a.y) a new segment (A) took place to the south of segment $C$, near the RTJ. Segment A corresponds to the off-axis trace of the presentday CIR segment 1 . Since $\sim 2.6 \mathrm{Ma}$, it has lengthened to the north and the south reaching $40 \mathrm{~km}$ long at the present time. Before $\sim 1.3 \mathrm{Ma}$ (between A2.y and AJ.o), segment $\mathrm{A}$ was bounded to the north by discontinuity $C-A$, which is probably a small right-stepping offset. However, for this period the lack of wellconstrained magnetic anomaly on segment $A$ does not allow an accurate estimation of this offset. At $\sim 1.3 \mathrm{Ma}$, discontinuity C-A became discontinuity $B-A$, which offsets segments $A$ and $B$ in a right-stepping manner by $\sim 16 \mathrm{~km}$ from AJ.o to $A 1$ and by $20 \mathrm{~km}$ at the present time.

The analysis of bathymetric and magnetic data has shown that the discontinuity D-C is a very short-lived feature. It appeared at $\sim 3 \mathrm{Ma}$ (between A2a.0 and A2a.y) and disappeared at $\sim 1.3 \mathrm{Ma}$ (between A2.y and AJ.o). Its "birth" and "death" are associated to spreading rate contrasts between segments $C$ and $D$. The distance between isochrons A2a.o and A2a.y shows an asymmetry of spreading to the south of discontinuity D-C, while the spreading to the north is symmetric (Figure 6b). Furthermore, bathymetric data show a large trough on the east flank, between A2a.o and
A2a.y, to the south of discontinuity D-C (thin dotted line in Figure 5), which has no conjugate on the opposite flank. This bathymetric trough can be interpreted as a relic of an axial valley and so suggests that the offset $D-C$ results from a CIR axis jump to the southwest of $\sim 8 \mathrm{~km}$ rather than a continuous asymmetry. In the same way, between A2.y and AJ.o, an asymmetry of spreading is observed to the south of discontinuity D-C, while the spreading is symmetric to the north (Figure 6b). A large bathymetric trough is also observed on the west flank, between A2.y and AJ.o and to the south of discontinuity D-C (thin dotted line in Figure 5), without a conjugate feature on the east flank. As previously, we can interpret this trough to be a part of a former axial valley. So, we suggest that the offset D-C was suppressed by a CIR axis jump, of $\sim 8 \mathrm{~km}$, to the northeast rather than by a continuous asymmetry. Such CIR jumps have been already proposed to explain the asymmetry observed between anomaly 1 and the CIR axis [Honsho et al., 1996]. On segment $A$ the jump has left, on the west flank, a large topographic trough interpreted as a fossil axial valley and characterized by high magnetization [Honsho et al., 1996]. The asymmetry, which is greater for segment $B$ (i.e., segment 2) than for the segment A (i.e., segment 1) (Figure 6b), has increased the offset A-B.

\section{SEIR Abyssal Hill System}

Although the bathymetric and magnetic coverage of the SEIR domain near RTJ is more restricted than along the CIR, the structure of the SEIR domain looks less complex than along the CIR. The linear isochrons of the SEIR, especially on the west flank, show that the first segment of the SEIR south of the RTJ is 
a long-lived feature, which was not disrupted by NTDs since $9 \mathrm{Ma}$ at least. Owing to the limited bathymetric coverage, we have analyzed the SEIR abyssal hill system only for this segment and for the last $1 \mathrm{Myr}$.

The pattern of abyssal hills (Figure 7) over the SEIR has been enhanced by calculating the principal curvatures around each pixel of the bathymetric grid following Shaw and Lin [1993]. The abyssal hills have a mean strike of $N 138^{\circ} \mathrm{E}$ and are regularly occurring every $4-5 \mathrm{~km}$. Like the axial volcanic ridge on the SEIR inner valley floor, they are crowned by numerous conicshaped peaks, indicating that they result to some extent from volcanic processes. Close to the axis, the abyssal hills are asymmetric in shape with steep inward facing faults and more gentle slope facing toward the flanks. Outward facing faults become as numerous as inward facing faults at $18 \mathrm{~km}(\sim 0.7 \mathrm{Ma})$ from the axis, producing a typical horst- and graben-type relief. The most striking features in the organization of the off-axis terrain is the almost perfect symmetry between the ridges on each side of the SEIR axis. Figure 7 shows that the successive ridges are found at almost the same age on each flank. Although the southwestern flank has been uplifted near the Antarctic RTJ trace, the similarity between the amplitude of the abyssal hills on each flank is also noticeable (dotted lines in Figure 7). This spatial relationship is in agreement with the work of Kappel and Ryan [1986] and Pezard et al. [1992], who explained the generation of the rift flanking topography of the intermediate-spreading Juan de Fuca Ridge and Galapagos Ridge, respectively. They proposed a cyclic process in which the volcanic construction of a crestal ridge within the rift valley, accompanying active crustal accretion, is followed by a collapse and splitting of the summit region of this ridge when there is a reduced melt supply to the axial magma chamber. Each part of the axial ridge is then shifted on the flank, producing the observed symmetric organization of abyssal hills. The topography of the SEIR flanks probably results from such cyclic processes. The formation of a new SEIR crestal ridge, due to an increase of volcanic constructions, is often associated with a slight northward lengthenıng of the ridge, creating the en échelon pattern of the Antarctic RTJ trace [see Sauter et al., 1997, Figure 10). This small lengthening of the SEIR is coincident with the redistribution of the deformation at the RTJ when it is relocated to the north [Sauter et al., 1997]. We thus suggest that both the increase of SEIR volcanic processes and the redistribution of deformation at the RTJ favor small lengthening of the SEIR.

\section{Results and Discussion}

The analysis of the bathymetric and magnetic data of the CIR domain near RTJ has shown that since at least $8 \mathrm{Ma}$, the CIR was lengthening continuously, more or less rapidly, to the southeast and that periods of asymmetric and symmetric spreading have alternated. Furthermore, the short-lived NTDs as well as the segments that lengthen or shorten along the ridge axis have revealed that the CIR segmentation is unstable.

The triple junction configuration also changes through time. We have shown that an axial discontinuity has existed between the CIR and SEIR axis from 9 to $3 \mathrm{Ma}$ and disappeared afterward. Moreover, the SEIR is characterized by frequent occurrence of periods of discontinuous lengthening, which generated the en échelon pattern of the Antarctic RTJ trace.

The third branch of the triple junction, i.e., the SWIR, propagates in a preexisting seafloor created at the CIR and SEIR axes. However, contrary to the SEIR and the CIR, there is no "normal" seafloor spreading on the SWIR near the RTJ, the first spreading segment closest the RTJ is at only $200 \mathrm{~km}$ from it, and tectonic processes are predominant in this domain [Sauter et al., 1997]. Sauter et al. [1997] proposed that the evolution of the SWIR domain is probably related to different localizations and distributions of strain which are in turn controlled by changes of the triple junction configurations. We thus suggest that both the evolution of the segmentation of the CIR and the SEIR and the modes of propagation of the SWIR domain are strongly related to changes of the triple junction configuration.

\subsection{Capricorn RTJ Trace: A Record of the Past RTJ Configuration}

The velocity triangles [Patriat and Courtillot, 1984] of the RTJ describe the offset evolution between the CIR and the SEIR. To built these triangles, we used the CIR and SEIR spreading rates (Table 2) and the directions of the isochrons and of the RTJ traces (Figure 5). The CIR and SEIR spreading directions are given by the rotations of Royer et al. [1997] for the CIR and Royer and Schlich [1988] for the SEIR. Owing to the lack of recognizable magnetic anomalies, the SWIR spreading rate, as well as the SWIR spreading direction, is given by the rotation of Chu and Gordon [1999].

Between A2a.o and A4.o, the predicted Capricom RTJ trace is associated with $14-23 \mathrm{~km}$ long offsets (Figure $6 \mathrm{~d}$ ). The velocity triangle built for the period between A3.o and A2a.o (Figure 8a) shows a $1.8 \mathrm{~km} / \mathrm{Myr}$ offset lengthening rate between the CIR and SEIR axes. This rate is small but remains significant. When integrated between $\mathrm{A} 3 \mathrm{a} .0$ and $\mathrm{A} 2 \mathrm{a} .0$ ( $\sim 3 \mathrm{Ma}$ ), it is equivalent to a finite $\sim 5.4 \mathrm{~km}$ long offset between the two ridges. Adding this offset to the initial $14.2 \mathrm{~km}$ long offset at A3a.o (Figure 6d) results in a $19.6 \mathrm{~km}$ long offset at $\mathrm{A} 2 \mathrm{a} .0$, which is consistent with the $19.5 \mathrm{~km}$ long offset measured at this time (Figure $6 \mathrm{~d}$ ).

For the period between A2a.y and A1, there is no offset between the SEIR and CIR isochrons (Figure 6d), whereas the velocity triangle (Figure $8 \mathrm{~b}$ ) shows an offset lengthening rate of $6 \mathrm{~km} / \mathrm{Myr}$ between the CIR and SEIR axes, which means that the offset increased by $10.8 \mathrm{~km}$ between A2a.y and A1. One possibility is that the progressive curvature of the SEIR and CIR isochrons and abyssal hills near the Capricorn RTJ trace (Figure 5) compensates for small offsets $(<6-7 \mathrm{~km})$, leaving apparent zero offsets. From $\sim 2.6 \mathrm{Ma}$ (A2a.y) to $\sim 0.5 \mathrm{Ma}$, the abyssal hills of the SEIR and the CIR curve gently near the predicted Capricom RTJ trace to connect each other (Figure 7). During this period the predicted Capricorn RTJ trace corresponds to a relative low along these continuous abyssal hills. The abyssal hills begin to curve at $\sim 5 \mathrm{~km}$ from the predicted Capricorn RTJ trace at AJ.o, whereas they curve farther away from this trace $(\sim 10 \mathrm{~km})$ at $0.5 \mathrm{Ma}$ as the offset at the RTJ is increasing. Removing this curvature by straightening the CIR and SEIR isochrons results in a $6 \mathrm{~km}$ long offset along the Capricorn RTJ trace at Al. In the same way, the offsets at AJ.y and AJ.o should be $\sim 6$ and $\sim 5.5 \mathrm{~km}$ long, respectively. The lack of well-constrained magnetic anomalies on CIR segment A, from A2a.y to A2.y, does not allow estimation of the offset for this period. However, taking into account a $6 \mathrm{~km}$ long offset at $\mathrm{A} 1$ and the offset evolution given by the velocity triangle for the A2a.y-A1 period, the CIR axis should have been offset by $4.8 \mathrm{~km}$ to the south of the SEIR axis at A2a.y. The velocity triangle built for the period between A2a.y and A2.y (Figure $8 \mathrm{~b}(\mathrm{left})$ ) shows that this small left-stepping offset remained roughly the same during this period. This unusual configuration of the CIR and SEIR axes could explain the unusual direction of the isochrons and abyssal hills of the SEIR, 


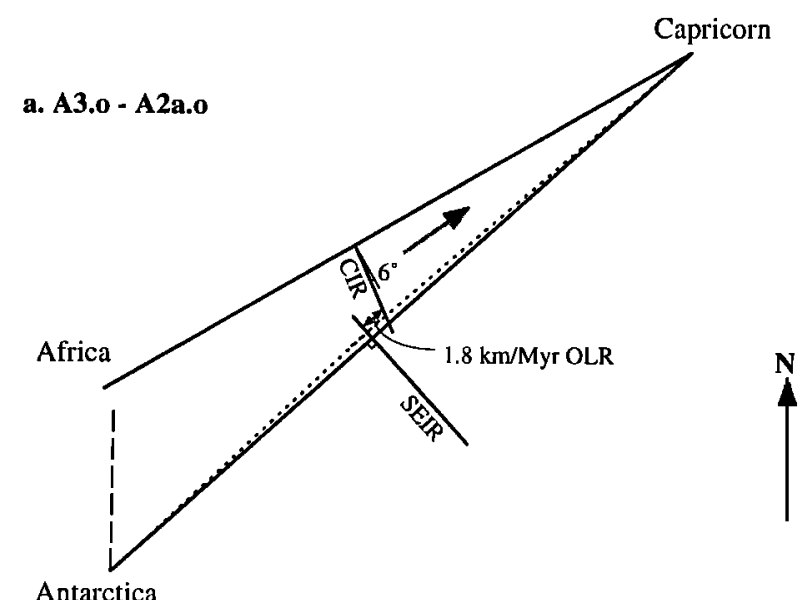

Antarctica
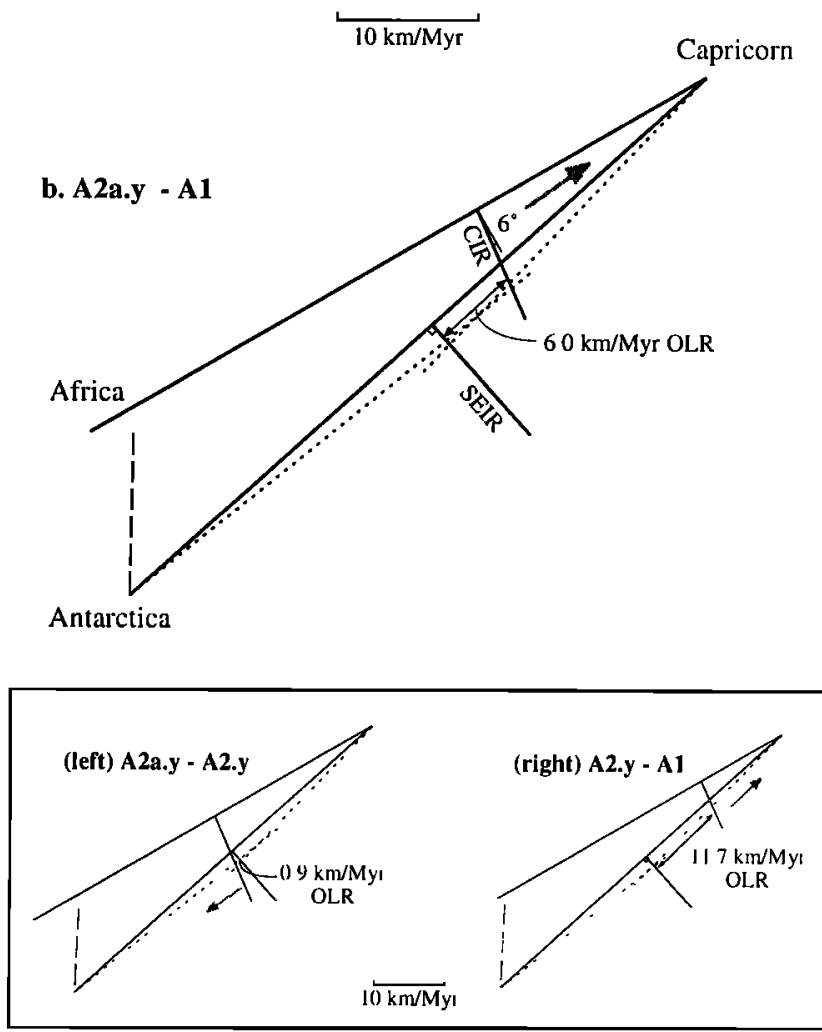

Figure 8. Velocity triangles built for (a) the period between anomaly $3 \mathrm{a}$ old and anomaly $2 \mathrm{a}$ old and (b) the period between anomaly $2 a$ young and anomaly 1 . The Central Indian Ridge and Southeast Indian Ridge spreading directions are given by the rotations of Royer et al. [1997] and Royer and Schlich [1988], respectıvely. The Southwest Indian Ridge spreading direction and rate are given by the rotation of $\mathrm{Chu}$ and Gordon [1999] (longdashed line). The short-dashed lines are the 0.8-2.6 Ma (Figure 8a) and 3.6-6.6 Ma (Figure $8 \mathrm{~b}$ ) mean azimuths of the African and Capricorn triple junction traces taken from Figure 5 . The offset between the Central Indian Ridge and Southeast Indian Ridge axes increases at different rates, varying between 0.9 and $11.7 \mathrm{~km} / \mathrm{Myr}$ (OLR, offset lengthening rate). The shaded arrows indicate the general displacement of the Central Indian Ridge axis with respect to the Southeast Indian Ridge axis. The Rodrigues Triple Jucntion trace on the African plate is not shown because northward relocalizations of the Southwest Indian Ridge rifting may have enclosed part of Central Indian Ridge preexisting crust within the Antarctic plate, leaving little evidence for a precise location of the trace on the African plate [Mitchell and Parson, 1993; Sauter et al., 1997]. which curve to the west toward the predicted Capricom RTJ trace at A2a.y-A2.y (Figures 5 and 7). The transition between this configuration and the present one, where the CIR axis is offset to the north of the SEIR axis, occurred between A2.y and AJ.o, when the CIR spreading was highly asymmetric (Figure $8 \mathrm{~b}($ (right)). This asymmetry is probably related to a CIR axis jump to the northeast at the same time than another ridge jump on CIR segment C. Finally, when the offset is too large $(>6-7 \mathrm{~km})$ to be compensated by a long-wavelength curvature of the abyssal hills of the SEIR and the CIR, the deformation is focused in a NTD that takes place at the RTJ, and thus the axes are no longer connected. However, a curvature of the abyssal hills of the CIR and the SEIR toward the NTD can still be observed in some places. At the present time, for example, the CIR axis curves to the west toward the RTJ, and a $5.5 \mathrm{~km}$ long apparent offset can be measured (Figures 5 and $6 \mathrm{~d}$ ). If we straighten the CIR axis, the offset between the CIR and SEIR axes is $\sim 9 \mathrm{~km}$ long.

At about A3.o, for a short period of time, offsets of isochrons are no longer associated with a bathymetric low corresponding to a NTD but with a bathymetric high characterized by CIR axis-parallel structures that cross the discontinuity. Similar features have been previously described by Grindlay et al. [1991] for the NTDs of the south Mid-Atlantic Ridge. We suggest that the CIR features were produced during a period of high melt delivery and lengthening trough the NTD toward the SEIR flank. This lengthening occurred when the offset of the RTJ between A2a.o and A4.o was the smallest.

\subsection{Two Configurations for the RTJ}

The morphology of the Antarctic RTJ trace on the GLORIA images was one of the major reason for Mitchell and Parson [1993] to consider two modes of evolution for the RTJ: a discontinuous mode when the Antarctic RTJ trace is associated with a series of en échelon faults and a contınuous mode when the Antarctic RTJ trace corresponds to a long linear scarp. The bathymetric data over the triple junction traces have shown that the most recent period of continuous mode is shorter than previously defined by Mitchell and Parson [1993]: it extends from A2a.y to A1. Durng this period, the CIR and SEIR axes are connected, the SEIR is spreading symmetrically, and the CIR spreading is mostly symmetric but is asymmetric near the triple junction trace, producing more crust to the western flank. As previously mentioned, owing to spreading asymmetry and to differences in axis direction or in lengthening rates of the CIR and the SEIR, this RTJ configuration evolves rapidly ( $<2 \mathrm{Myr}$ ) into another configuration where there is a small offset between the CIR and SEIR axes (Figure 9b). The "appearance" of this offset, just after A1, coincides to a slight lengthening of the SEIR to the northwest as shown by the en échelon pattern of the Antarctic RTJ trace. Thus this suggests that a new period of discontinuous mode began just after Al. This period also corresponds to an asymmetric spreading period of the CIR (since A1) that increased the offset between the SEIR and CIR axes (Figure 9b). In contrast with the findings of Honsho et al. [1996], we consider that this asymmetry of the CIR spreading is the result of a CIR axis eastward jump and not of a very short-lived $(<0.5 \mathrm{Ma}$ ) northward propagation of the SEIR (of $>25 \mathrm{~km}$ into CIR segment 1). We argue that no pseudo-fault of this propagating rift is observed on the bathymetric map (Figures 2a and $2 \mathrm{~b}$ ) and that not only CIR segment 1 but also CIR segment 2 shows the same asymmetric pattern (Figure 6b).

The main characteristic of the disco ntinuous mode is the offset between the CIR and SEIR axes. In the surveyed area this offset 
(a) Continuous mode
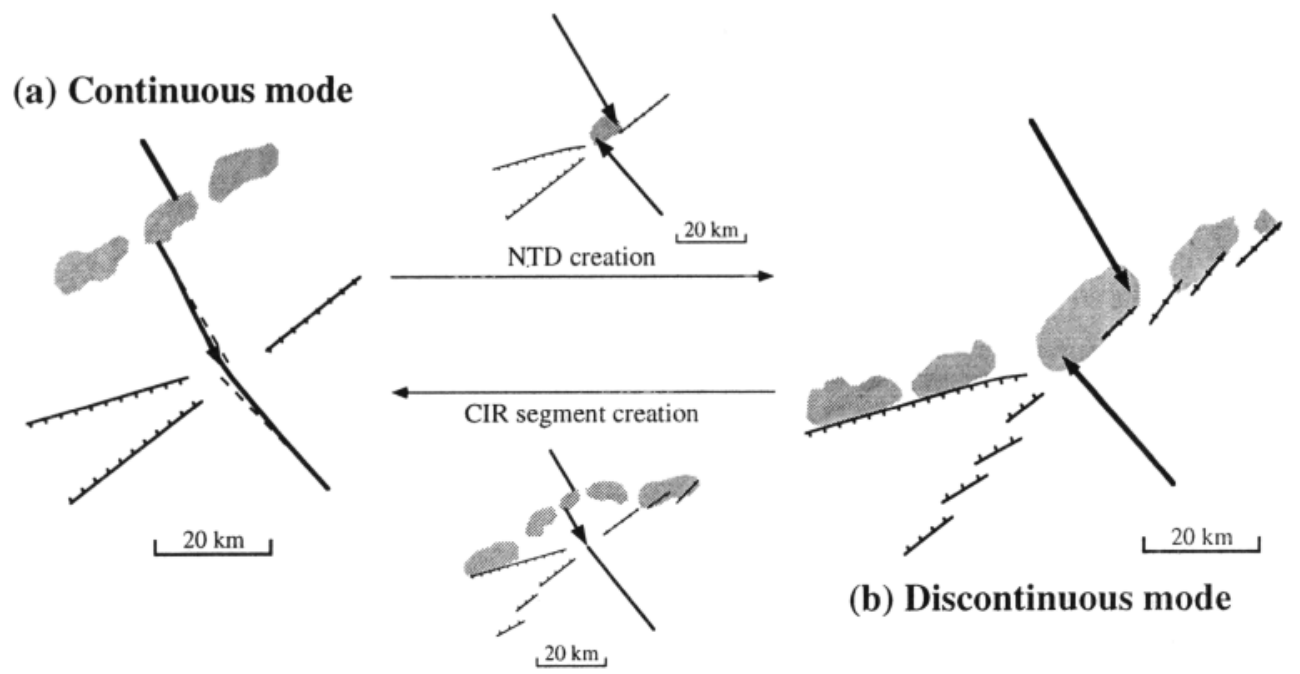

(b) Discontinuous mode

Figure 9. Schematic patterns of the two modes of evolution of the Rodrigues Triple Junction: (a) the continuous mode and (b) the discontinuous mode. During the continuous mode period, the Central Indian Ridge and Southeast Indian Ridge axes are connected. Owing to the spreading asymmetry and differences in axis direction or in lengthening rates of the Central Indian and Southeast Indian ridges, this triple junction configuration evolves rapidly ( $<2 \mathrm{Myr}$ ) into another mode where there is an offset between the Central Indian Ridge and Southeast Indian Ridge axes, which is the beginning of a discontinuous mode period. During this discontinuous mode period, the Southeast Indian Ridge propagates slightly $(<5 \mathrm{~km})$ toward the northwest every $0.5-1.1 \mathrm{Myr}$ according to the en échelon pattern of the Antarctic triple junction trace. The transition from a discontinuous mode to a continuous mode corresponds to the formation of a new Central Indian Ridge segment. See text for further details.

never exceeds $23 \mathrm{~km}$ (Figure 6d). During this mode, which extends from A4.0 to A2a.y, periods of symmetric and asymmetric spreading of the CIR and the SEIR alternated (Figures $6 \mathrm{~b}$ and $6 \mathrm{c}$ ). When these ridges are spreading asymmetrically, both are systematically producing more crust to the eastern flank by contrast to the continuous mode. Between A4.y and A2a.o, the asymmetry of CIR spreading allows to reduce the offset between the SEIR and CIR axes.

At about A2a.y the transition between the discontinuous mode and the continuous mode is associated with the appearance of a new CIR segment near the RTJ. The reason why this segment took place, at that time, is still unclear. However, we have observed that the "birth" of this segment is preceded by a southward axis jump in CIR segment $E$ which allows reduction, but not removal, of the offset at the RTJ. Moreover, at about the same time (A2a.y), segment $C$ lengthens through the NTD at the triple junction (crossed area in Figure 5). Both the southward axis jump and the lengthening in the southernmost segment of the CIR favor the connection between the CIR and the SEIR. This connection may result from a relocation of the southern tip of the CIR at the northern tip of the SEIR by another single small axis jump or by successive relocations of the southern tip of the CIR. In the latter case, the relocalizations are associated with a series of alternating small jumps and propagations of the axial volcanic zone in the NTD at the triple junction. The lack of well-identified magnetic anomalies and fine-scale bathymetric data does not allow us to better constrain the birth of segment $A$ and its evolution until A2. Once the new segment A has been created, the discontinuity A-C moves away from the RTJ and becomes the discontinuity between today's CIR segments 1 and 2 . At a longer timescale the morphology of the Antarctic RTJ trace (Figure 10), mapped with GLORIA side-scan sonar data [Mitchell and Parson, 1993] and our bathymetric data, shows another example of transition between periods of continuous and discontinuous mode. Figure 10 shows that as for the discontinuity between CIR

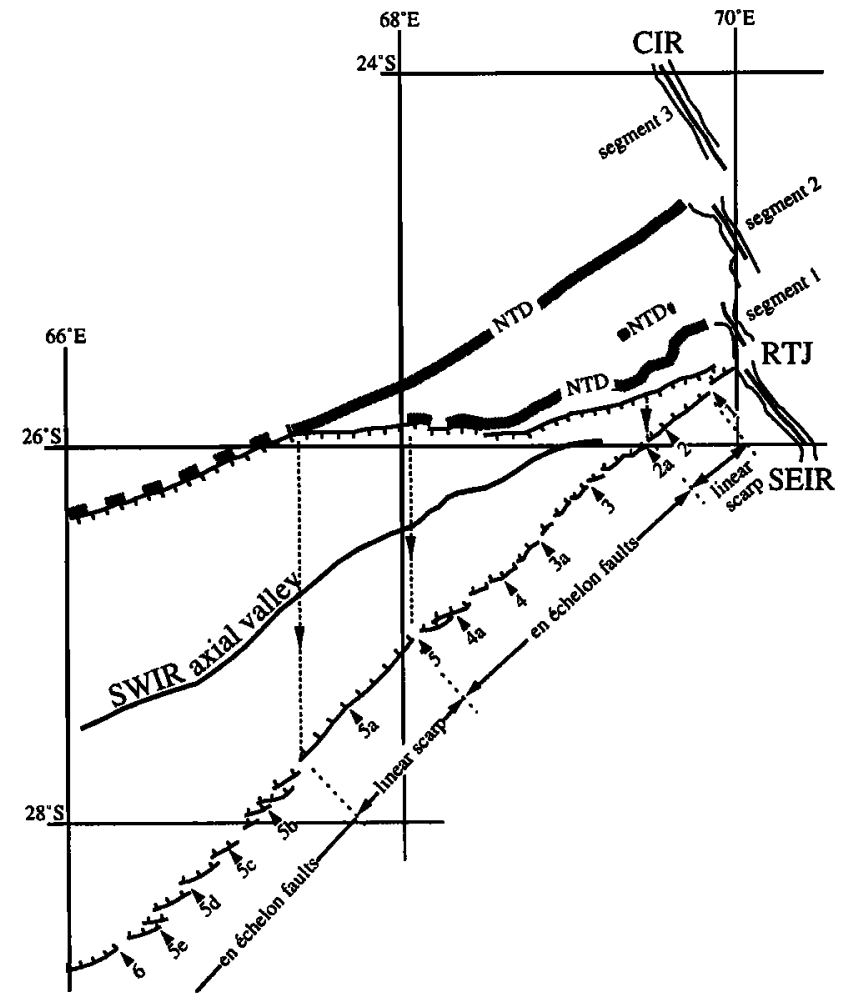

Figure 10. Schematic drawing of the triple junction traces, the three segments of the CIR and the segment of the SEIR, partly based on the GLORIA map over the SWIR valley (modified from Mitchell and Parson [1993]) and the Sea Beam maps over the Central Indian Ridge [Briais, 1995] and the Southeast Indian Ridge [Honsho et al., 1996]. Anomalies along the Antarctic triple junction trace are shown by solid triangles: anomalies 2 to 4 correspond to the younger edge of the anomalies shown in Figure 5; anomalies 4a to 6 are from Mitchell and Parson [1993] and correspond to the centers of the anomaly maxima. 
segments 1 and 2 , the discontinuity between today's CIR segments 2 and 3 has moved away from the RTJ at the beginning of a period of continuous mode, when a new CIR segment was taking place near the RTJ.

To summarize, the two modes of RTJ evolution are associated with the opening and the closure of offsets between the two adjacent spreading segments of the CIR and the SEIR, as previously suggested by Mitchell and Parson [1993]. The continuous mode where the CIR and SEIR axes are joined (Figure 9a) is unstable and evolves rapidly $(<2 \mathrm{Myr})$ into the discontinuous mode (Figure 9b) because the offset increases rapidly ( $-6 \mathrm{~km} / \mathrm{Myr}$; Figure $8 \mathrm{~b}$ ). This transition is associated with the formation of a NTD at the RTJ. The presence of a such NTD probably favors small discontinuous lengthening of the SEIR, which creates the en échelon pattern of the Antarctic RTJ trace (Figure 9b). This NTD stays at the RTJ, following the lengthening of the CIR, until a new CIR segment takes place and the offset between the SEIR and CIR closes. This transition to the continuous mode is related to the magmatic budget beneath the adjacent segments that controls the lengthening of these segments, their propagation through the small nontransform discontinuity, and their connection at the triple junction. Although the continuous mode is not stable and evolves quickly to the discontinuous mode, the nontransform offset between the CIR and SEIR axes never exceeds $23 \mathrm{~km}$ for the last $8 \mathrm{Myr}$ because small CIR axis jumps and asymmetric spreading counterbalance the spreading rate difference between the SEIR and the CIR. Reconstructions of the junction of the two ridges show that no large offset has occurred at the RTJ for the last 35 Myr [Patriat, 1987]. We suggest that the formation of new CIR segments facing the SEIR segment takes place to fit on the relative continuity of the mantle upwelling beneath the CIR and SEIR axes. Therefore the succession of continuous and discontinuous modes allows to keep a regional RRR (ridge-ridgeridge) configuration for the triple junction which is an energetically more favorable configuration [Patriat and Courtillot, 1984].

\subsection{Further Implications on Mid-Oceanic Ridge Segmentation}

Two main hypotheses have been proposed to explain the evolution of ridge segmentation: a tectonic control and a magmatic control [e.g., Tucholke et al., 1997]. According to the magmatic hypothesis, segments are positioned above mantle upwelling centers or focused zone of rising melt [Whitehead et al., 1984; Lin et al., 1990]. The temporal and spatial variability of along-axis magmatic input may thus control the evolution of spreading segments and in the same way the evolution of NTDs. By contrast, the tectonic hypothesis suggests that ridge segments fragment, forming new NTDs, and adjust in orientation mainly following changes in the pole of relative motion [Ménard and Atwater, 1968; Lonsdale, 1985].

Although the triple junction context is particular, the study of the origin and evolution of the segmentation of the southern CIR gives some clues to testing these competing hypotheses. According to our model a new CIR segment took place near the RTJ following a southward propagation of a CIR segment and an asymmetry of spreading. The restriction of this asymmetry to the southem tip of the propagating segment probably excludes a change in the pole of relative motion, which should affect the entire plate boundary rather than only a small part. We therefore suggest that the origin of the southern CIR segmentation is controlled by magmatic processes. However, the periods of propagation and asymmetry, which result in the creation of a new segment, are short ( $<1.5 \mathrm{Myr}$ ) suggesting that they result more from variations of shallow magmatic processes than from deepseated ones. As the mantle upwelling beneath the CIR and SEIR axes is continuous but changes strike at the triple junction [West et al., 1995], the creation of a new CIR segment may be associated with the creation of a new magma reservoir which is not in a vertical line with the mantle upwelling on the CIR but rather is aligned with the SEIR axis. Then the observed asymmetry could correspond to displacements of this magma source with respect to the CIR mantle upwelling [Palmer et al., 1993], and/or by relocations of the neovolcanic zone [Grindlay et al., 1991]. In the first case, the migration of the magma source would have the effect of heating the overlying lithosphere and creating new zones of weakness where spreading and crustal accretion relocate [Palmer et al., 1993]. In the second case, the melt freezing in shallow crustal level magma chambers, between phases of magma supply, creates a barrier for the ensuing magmatic pulse which may be deflected to the older and faulted crust, resulting in a relocation of the neovolcanic zone [Grindlay et al., 1991]. Whatever the origin of the asymmetry, shallow magmatic processes probably play a dominant role in controlling the initiation of the CIR segmentation at the triple junction.

\section{Conclusions}

The analysis of multibeam bathymetric data and magnetic data of the three Indian ridge domains around the RTJ reveals the evolution of the CIR segmentation, in its southern part, and its relations to the evolution of the RTJ since anomaly 4 (8 Ma). It suggests the following conclusions.

1. The CIR was lengthening continuously, more or less rapidly, to the southeast with alternating periods of asymmetric and symmetric spreading. The short-lived NTDs as well as the segments that lengthen or shorten along the ridge axis have revealed that the CIR segmentation is unstable.

2. The RTJ evolves between two modes: a continuous mode where CIR and SEIR axes are connected and a discontinuous mode where the two ridge axes are offset. Therefore these two modes are controlled by the opening and the closing of offsets between two adjacent spreading segments of the CIR and the SEIR.

3. Owing to spreading asymmetry and differences in axis direction or in lengthening rates of the CIR and the SEIR, the continuous mode is unstable and evolves rapidly $(<2 \mathrm{Myr})$ into a discontinuous mode. This transition is associated with the formation of a NTD at the RTJ. The presence of such a NTD probably favors small discontinuous lengthening of the SEIR which create the en échelon pattern of the Antarctic RTJ trace. This discontinuous mode is more stable and can evolve to a continuous mode only through the formation of a new CIR segment, near the RTJ, which takes place facing the northern SEIR segment. The evolution of the RTJ configuration and the evolution of the CIR segmentation are thus closely related.

4. The succession of continuous and discontinuous modes allows to keep a regional RRR (ridge-ridge-ridge) configuration for the triple junction.

Acknowledgments. We would like to thank Kensaku Tamaki and Hiromi Fujimoto, who allowed us to use the Sea Beam data collected during the KH93-3 cruise by the R/V Hakuro Maru in 1993. We want to thank Peter Herzig, who kindly gave us a copy of digital Sea Beam data collected during the R/V Sonne during the Gemino cruises. We also want to thank Peter Halbach for the Hydrosweep data obtained during the Hydrock I cruise by the R/V Meteor in 1995. Lindsay Parson kindly 
allowed us to access the GLORIA data of the cruise 23 of the RRS Charles Darwin conducted by the Institute of Oceanographic Sciences Deacon Laboratory (U.K.). We also thank an anonymous JGR Associate Editor and an anonymous reviewer for helpful comments and careful corrections of the manuscript. Figures were created using the CETIS software developed at EOPG Strasbourg [Boulanger et al., 1992] and the public domain GMT software [Wessel and Smith 1991]. This research was supported by CNRS-INSU, Géosciences Marines program.

\section{References}

Boulanger, D., M.-O. Boulanger, M. Munschy, D. Sauter, and J.-D. Tissot, Cetis: A new computer software to display marne geophysical data, improve navigation using SeaBeam crossings, grid data and process images (abstract), Ann. Geophys., Suppl. 10, 102, 1992.

Bourillet, J.-F., C. Edy , F. Rambert, C. Satra, and B. Loubrieu, Swath mapping system processing: bathymetry and cartography, Mar. Geophys. Res., 18, 487-506, 1996.

Briais, A., Structural analysis of the segmentation of the Central Indian Ridge between $20^{\circ} 30^{\prime} \mathrm{S}$ and $25^{\circ} 30^{\prime} \mathrm{S}$ (Rodriguez Triple Junction), Mar. Geophys. Res., 17, 431-467, 1995.

Cande, S. C., and D. V. Kent, Revised calibration of the geomagnetic polarity tumescale for the Late Cretaceous and Cenozoic, J. Geophys. Res., 100, 6093-6095, 1995.

Chu, D., and R. G. Gordon, Evidence for motion between Nubia and Somalia along the Southwest Indian ridge, Nature, 398, 64-67, 1999.

De Moustier, C., State of the art in swath bathymetry survey system, Int. Hydrogr. Rev., 65(2), 25-54, 1988.

Grindlay, N. R., P. J. Fox, and K. C. Macdonald, Second-order ridge axis discontinuities in the South Atlantic: morphology, structure, and evolution, Mar. Geophys. Res., 13, 21-49, 1991.

Halbach, P., N. Blum, W. Plüger, M. van Gerven, J. Erzınger, and SO 92 Shipboard Scientific Party, The Sonne Field-First massive sulfides in the Indian Ocean, InterRidge News, 4, 12-15, 1995.

Honsho, C., K. Tamaki, and $\mathrm{H}$. Fujimoto, Three-dimensional magnetic and gravity studies of the Rodriguez Triple Junction in the Indian Ocean, J. Geophys. Res., 101, 15,837-15,848, 1996.

Kappel, E. S., and W. B. F. Ryan, Volcanic episodicity and a non-steady state rift valley along northeast Pacific spreading centers: Evidence from SeaMARC 1, J. Geophys. Res., 91, 13,925-13,940, 1986.

Lin, J., G. M. Purdy, H. Schouten, J. C. Sempéré, and C. Zervas, Evidence from gravity data for focused magmatic accretion along the Mid-Atlantic Ridge, Nature, 344, 627-632, 1990.

Lochte, K., P. Halbach, and B.-W. Flemming, Biogeochemical fluxes in the deep-sea and investigations of geological structures in the Indian Ocean, Cruise No. 33, 22 September - 30 December 1995, Meteor Ber., 96-5, 160 pp., Univ. Hamburg, Hamburg, Germany, 1995.

Lonsdale, P., Nontransform offsets of the Pacific-Cocos plate boundary, and their traces on the rise flank, Geol. Soc. Am. Bull., 96, 313-327, 1985.

McKenzie, D. P., and J. G. Sclater, The evolution of Indian Ocean since the late Cretaceous, Geophys. J. R. Astron. Soc., 25, 437-528, 1971.

Ménard, H. W., and T. M. Atwater, Changes in direction of sea floor spreading, Nature, 219, 463-467, 1968.

Mendel, V., D. Sauter, L. Parson, and J.-R. Vanney, Segmentation and morphotectonic variations along a super slow-spreading center: The Southwest Indian Ridge $\left(57^{\circ} \mathrm{E}-70^{\circ} \mathrm{E}\right)$, Mar. Geophys. Res., 19, 505533, 1997.

Mitchell, N. C., Distributed extension at the Indian Ocean triple junction, J. Geophys. Res., 96, 8019-8043, 1991 a.

Mitchell, N. C., An evolving ridge system around the Indian Ocean triple junction, Mar. Geophys. Res., 13, 173-201, 1991b.

Mitchell, N. C., and L. M. Parson, The tectonic evolution of the Indian Ocean triple junction, anomaly 6 to present, J. Geophys. Res., 98, 1793-1812, 1993.

Mitchell, N. C., J. Escartin, and S. Allerton, Detachment faults at midocean ridges garner interest, Eos Trans. AGU, 79, 127, 1998.

Munschy, M., and R. Schlich, The Rodriguez Triple Junction (Indian Ocean): Structure and evolution for the past one million years, Mar. Geophys. Res., 11, 1-14, 1989.

Palmer, J., J.-C. Sempéré, D. M. Christie, and J. Phipps-Morgan, Morphology and tectonics of the Australian-Antarctic Discordance between $123^{\circ} \mathrm{E}$ and $128^{\circ} \mathrm{E}$, Mar. Geophys. Res., 15, 121-152, 1993.

Patrat, P., Reconstitution de l' évolution du système de dorsales de l'océan Indien par la méthode de la cinématique des plaques, mémoire hors-série, 308 pp., Territoire des Terres Austr. et Antarct. Fr., Paris, 1987.

Patriat, P., and V. Courtillot, On the stability of the triple junctions and its relation to episodicity in spreading, Tectonics, 3, 317-332, 1984.

Patriat, P., and L. Parson, A survey of the Indian ocean triple junction trace within the Antarctic plate implications for the junction evolution since 15 Ma, Mar. Geophys. Res., II, 89-100, 1989.

Patriat, P., and J. Ségoufin, Reconstruction of the central Indian Ocean, Tectonophysics, 155, 211-234, 1988.

Patrat, P., D. Sauter, M. Munschy, and L. M. Parson, A survey of the Southwest Indian Ridge axis between Atlantis II fracture zone and the Indian Ocean triple junction: Regional setting and large scale segmentation, Mar. Geophys. Res., 19, 457-478, 1997.

Pezard, P. A., R. N. Anderson, W. B. F. Ryan, K. Becker, J. C. Alt, and P. Gente, Accretion, structure and hydrology of intermediate spreadingrate oceanic-crust from drillhole experiments and seafloor observations, Mar. Geophys. Res., 14, 93-123, 1992.

Plüger, W. L., P. M. Herzig, K. P. Becker, G. Deissmann, and D. Schöps, Discovery of hydrothermal fields at the Central Indian Ridge, Mar. Min., 9, 73-86, 1990.

Renard, V., and J.-P. Allenou, Le Seabeam, sondeur à multifaisceaux du N/O Jean Charcot: Description, évaluation et premiers résultats, Int. Hydrogr. Rev., 56, 35-71, 1979.

Rommevaux-Jestin, C., C. Deplus, and P. Patriat, Mantle Bouguer anomaly along an ultra-slow spreading ridge: Implications for accretionary processes and comparison with results from central MidAtlantic Ridge, Mar. Geophys. Res., 19, 481-503, 1997.

Royer, J. Y., and R. Schlich, Southeast Indian Ridge between the Rodriguez triple junction and the Amsterdam and Saint-Paul islands: Detailed kinematics for the past 20 m.y., J. Geophys. Res., 93, 13,524$13,550,1988$.

Royer, J. Y., R. G. Gordon, C. DeMets, and P. R. Vogt, New limits on the motion between India and Australia since chron 5 (11 Ma) and implications for lithospheric deformation in the equatorial Indian Ocean, Geophys. J. Int., 129, 41-74, 1997.

Sauter, D., V. Mendel, C. Rommevaux-Jestin, P. Patriat, and M. Munschy, Propagation of the Southwest Indian Ridge at the Rodrigues Triple Junction, Mar. Geophys. Res., 19, 551-565, 1997.

Schlich, R., M. Munschy, J.-M. Marthelot, J.-Y. Royer, and M. Schaming, Les campagnes du N.O. Jean Charcot sur le point triple de Rodriguez (océan Indien): Premiers résultats, Bull. Soc. Géol. Fr., 8, 693-697, 1987.

Schlich, R., et al., Résultats préliminaires de la campagne océanographique Marion-Dufresne 61 sur la dorsale centrale indienne entre $21^{\circ}$ et $25^{\circ} 30^{\prime}$ S, C. R. Acad. Scl., 309, 1765-1772, 1989.

Shaw, P. R., and J. Lin, Causes and consequences of variations in faulting style at the Mid-Atlantic Ridge, J. Geophys. Res., 98, 21,839-21,851, 1993.

Tapscott, C. R., P. Patriat, R. L. Fisher, J. G. Sclater, H. Hoskins, and B. Parsons, The Indian Ocean Triple Junction, J. Geophys. Res., 85, $4723-4739,1980$.

Tucholke, B. E., J. Lin, M. C. Kleinrock, M. A. Tivey, T. B. Reed, J. Goff, and G. E. Jaroslow, Segmentation and crustal structure of the western Mid-Atlantic Ridge flank, $25^{\circ} 25^{\prime}-27^{\circ} 10^{\prime} \mathrm{N}$ and $0-29$ m.y., $J$. Geophys. Res., 102, 10,203-10,223, 1997.

Wessel, P., and W. H. F. Smith, Free software helps map and display data, Eos Trans. $A G U, 72,441,445-446,1991$.

West, B. P., H. Fujimoto, C. Honsho, K. Tamaki, and J.-C. Sempéré, A three-dimensional gravity study of the Rodrigues Triple Junction and Southeast Indian Ridge, Earth Planet. Sct. Lett., 133, 175-184, 1995.

Whitehead, J. A., H. J. B. Dick, and H. Schouten, A mechanism for magmatic accretion under spreading centres, Nature, 312, 146-148, 1984 .

V. Mendel, Southampton Oceanography Centre, Challenger Division for Seafloor Processes, Empress Dock, Southampton SO14 3ZH, England, U.K. (vxm@soc.soton.ac.uk)

M. Munschy and D. Sauter, Ecole et Observatoire des Sciences de la Terre, CNRS, UMR 7516, Institut de Physique du Globe, 5 rue René Descartes, F-67084 Strasbourg Cedex, France. (mmunschy@eost.u-strasbg.fr; dsauter@eost.u-strasbg.fr)

P. Patriat, Institut de Physique du Globe de Paris, 4 Place Jussieu, F-75252 Paris Cedex 05, France. (ppa@ccr.jussieu.fr)

(Received June 14, 1999; revised February 21, 2000; accepted March 23, 2000) 